\title{
Development and validation of HPTLC method for niacin and simvastatin in binary combination
}

\author{
Pravish Kumar Tiwari, Padmakar Sathe
}

Department of Chemistry, Ramnarian Ruia College, Mumbai, India.

Email: pravishkumar1981@yahoo.com

Received 21 February 2010; revised 11 March 2010; accepted 28 March 2010.

\begin{abstract}
A simple, sensitive and validated HPTLC method has been developed to determine Niacin and simvastatin simultaneously in synthetic mixture form. Chromatographic separation was achieved on a RP18 plate using a mixture of Methanol: Water: Acetic acid (60: 40:0.1) at a wavelength of $237 \mathrm{~nm}$. Linearity of the method was found to be in the concentration range of $5000.0-25000.0 \mu \mathrm{g} / \mathrm{ml}$ for niacin and $100.0-500.0 \mu \mathrm{g} / \mathrm{ml}$ for simvastatin with correlation coefficient greater than 0.999. The method can be used for simultaneous determination of Niacin and Simvastatin.
\end{abstract}

Keywords: HPTLC; Methanol; Niacin; Simvastatin

\section{INTRODUCTION}

Niacin (Figure 1) chemically designated as Pyridine 3 carboxylic acid reduce triglyceride, levels, is also effective for increasing serum HDL levels [1]. It has also been demonstrated that this drug lowers the incidence of coronary heart disease in humans [1]. A number of analytical methods have been developed for its determination in pharmaceutical formulations or in biofluids either alone or in combination with other drugs [2-8]. These include determination of niacin by liquid chromatography-mass spectrometry [9], HPLC [9-12], flow injection and spectrofluorimetric analysis.

Simvastatin (Figure 2), a hypolipidemic drug belong ing to the class of pharmaceuticals called statins is chemically designated as [(1S,3R,7R,8S,8aR)-8-[2-[(2R, 4R) -4-hydroxy-6-oxo-oxan-2-yl] ethyl]-3,7-dimethyl-1,2,3,7, 8,8ahexahydronaphthalen-1-yl]2,2-dimethy-lbutanoate. It is used for the treatment of hypercholes-terolemia [13]. An HMG-CoA reduces ase inhibitor, acts by decreasing cholesterol synthesis and by increasing low density lipoprotein (LDL) catabolism via increased LDL receptor activity [14]. Different analytical methods have been reported for the determination of simvastatin, which in- clude HPLC [15-17], HPLC-MS/MS [18], spectrophotometer [19].

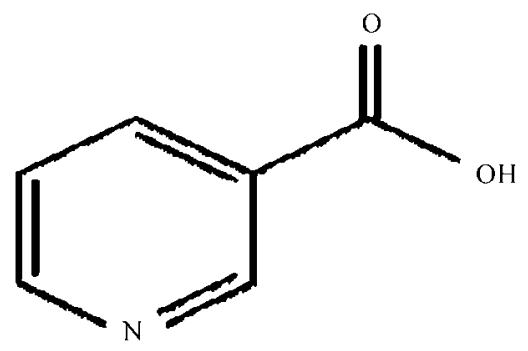

Figure 1. Niacin.<smiles>CCC(C)(C)C(=O)O[C@H]1C[C@@H](C)C=C2C=C[C@H](C)[C@H](CC[C@@H]3C[C@@H](O)CC(=O)O3)[C@H]21</smiles>

Figure 2. Simvastatin.

It was found that Simvastatin plus niacin provides marked clinical and angiographic ally measurable benefits in patients with coronary disease and low HDL levels [20]. The US Food and Drug Administration (FDA) has approved a fixed-dose combination of niacin and simvastatin for use in patients with complex lipid abnormalities where treatment with niacin or simvastatin alone is not sufficient [21] The FDA has approved maximum dose of niacin $1000 \mathrm{mg}$ and $20 \mathrm{mg}$ of simvastatin per tab. The combine dosage form of Niacin and simvastatin are available in market. 
According to the information collected from literature there is no reported method for simultaneous determination of Niacin and simvastatin. In the present work we have focused on deciding the optimum chromatographic conditions for the simultaneous determination of Niacin and simvastatin in a pharmaceutical preparation.

We describe in this paper a simple, sensitive and validated HPTLC method for the simultaneous determination of Niacin and Simvastatin. The developed method can be applied successfully for quality control and for other analytical purposes.

\section{MATERIAL AND METHODS}

\subsection{Chemicals and Reagents}

Niacin and simvastatin reference substances respectively were taken from Precise Pharma (Turbhe, mumbai). Methanol (HPLC grade), Triethyl amine and acetic acid (analytical reagent grade) were purchased from Merck (Mumbai). All excepients used were of pharmaceutical grade.

\subsection{Chromatographic Conditions}

The chromatographic estimation were performed using RP18 pre-coated on aluminum sheet $(10 \times 10 \mathrm{~cm}$, prewashed with methanol and dried in oven at $50^{\circ} \mathrm{C}$ for 5 min) mobile phase, Methanol: Water: Acetic acid (60: 40:0.1), chamber and plate saturation time of $45 \mathrm{~min}$, migration distance allowed was $75 \mathrm{~mm}$, wavelength scanning was done at $237 \mathrm{~nm}$, keeping the slit dimension at $5 \times 0.45 \mathrm{~mm}$.

\subsection{Preparation of System Suitability Solution}

A Stock solution of niacin and simvastatin was prepared at about $100000 \mu \mathrm{g} / \mathrm{ml}$ and $2000 \mu \mathrm{g} / \mathrm{ml}$ respectively in diluent. Then dilute $1 \mathrm{ml}$ of stock solution to $10 \mathrm{ml}$ with diluent to give $10000 \mu \mathrm{g} / \mathrm{ml}$ and $200 \mu \mathrm{g} / \mathrm{ml}$ niacin and simvastatin respectively. Spotted $2.5 \mu \mathrm{l}$ of system suitability solution in five replicates. And found RSD of peak area and $\mathrm{Rf}$ is below $2 \%$.

\subsection{Determination of Simvastatin and Niacin in Their Combined Dosage Forms}

The content of twenty tablets where taken and weighed powder equivalent to Niacin $1000 \mathrm{mg}$ and $20 \mathrm{mg}$ simvastatin in $10.0 \mathrm{ml}$ volumetric flask add $6 \mathrm{ml}$ of diluent and flask was sonicated for $5 \mathrm{~min}$. The flask was sonicated and the volume was diluted to the mark with diluent. The above solution was filtered using what man filter paper No. 1 . Then diluted $1.0 \mathrm{ml}$ of filtrate to 10.0 $\mathrm{ml}$ with diluent.

\subsection{Linearity}

Linearity of the proposed method was checked by ana- lyzing solutions in the range of 5000-25000 $\mu \mathrm{g} / \mathrm{ml}$ for niacin $(5000,7500,10000,12500,15000,20000,25000$ $\mu \mathrm{g} / \mathrm{ml})$ and $100-500 \mu \mathrm{g} / \mathrm{ml}$ for simvastatin $(100,150,200$, $250,300,400,500 \mu \mathrm{g} / \mathrm{ml})$. Each level was made in triplicate and spot $2.5 \mu \mathrm{l}$ of each solution.

\subsection{Accuracy}

Method accuracy was performed by adding known amounts of niacin and simvastatin to the pre analyzed sample and then comparing the added concentration with the found concentration. Four levels of solutions were made which correspond to $0,50,100$ and $150 \%$ of the nominal analytical concentration. Each level was made in triplicate and spot $2.5 \mu \mathrm{l}$ of each solution.

\subsection{Specificity}

Commonly used exceipients (starch, microcrystalline cellulose and magnesium stearate, lactose,) were spiked in to a pre weighed quantity of drugs . The chromatogram was taken by appropriate dilution and the quantities of drug were determined.

\subsection{Precision}

For evaluating the within-day precision, results of six replicate analyses of samples were calculated on a single day. The between-day precision was calculated from the samples analyzed on different days.

\section{RESULTS}

In the present work conditions were optimized for the development and validation of a simple and accurate HPTLC method for the simultaneous determination of niacin and simvastatin in synthetic mixture form.

Method development was started with water and methanol in the ratio of 50:50 (v/v). At this composition although both components were resolved but peak shape were not good. With the mobile phase composition of Methanol: Water: Acetic acid (60:40:0.1) good resolution and better peak shape were obtained.

Under the described experimental conditions, sharp peaks that belong to niacin and simvastatin were obtained at retention factor of 0.23 and 0.57 minutes respectively as shown in Figure 3.

The developed chromatographic method was validated using ICH guidelines [22]. Validation parameters performed include linearity, specificity, accuracy and precission. The calibration curve was linear over the concentration range of 5000-25000 $\mu \mathrm{g} / \mathrm{ml}$ for niacin and 100 $500 \mu \mathrm{g} / \mathrm{ml}$ for simvastatin. The correlation coefficient in both cases were found to be greater than 0.999 which manifests a linear relationship between concentration and the peak area. The linear regression equation for niacin was found to be $\mathrm{Y}=3.2342 \mathrm{X}+149.26$ with correlation coeffi cient equal to 0.9999 . 
The linear regression equation for simvastatin was found to be $\mathrm{Y}=11.499 \mathrm{X}+4.8303$ with value of correlation coefficient equal to 0.9999 .

The recovery and the relative standard deviation for each of the analytes are given in Table 1 , Table 2 , Table 3 and Table 4 mean recovery for Niacin is found
$100.48 \%$ \& for simvastatin is found $99.80 \%$.

The results of three successive day and precision are presented in Table 5.

Chromatogram of niacin and simvastatin in sample in given in Figure 4 showing selectivity of the proposed method.

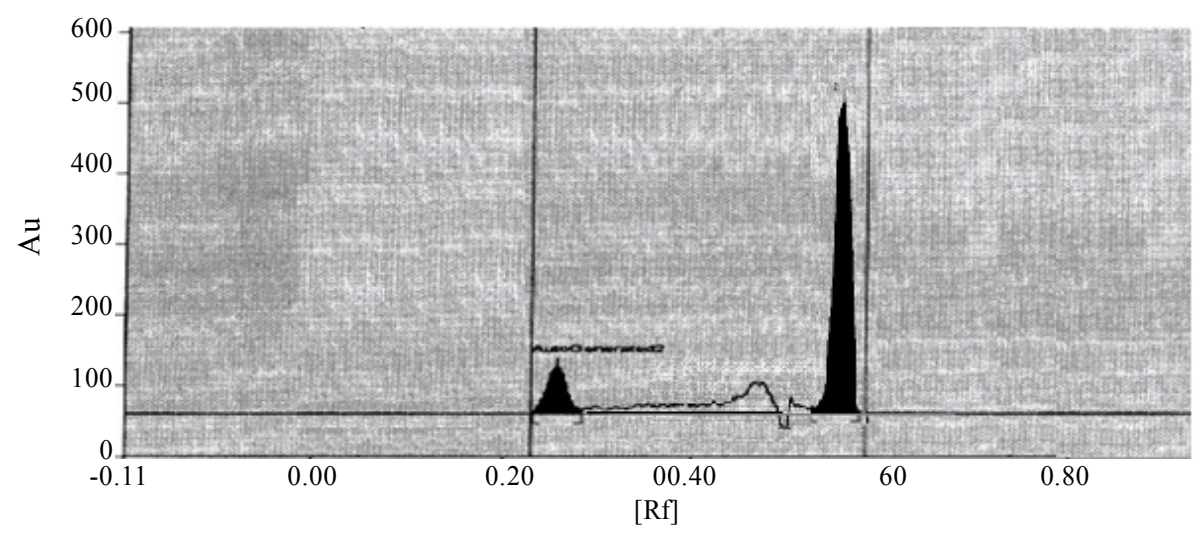

Figure 3. Chromatograms of Niacin and Simvastatin in standard solution.

Table 1. Accuracy of Niacin.

\begin{tabular}{|c|c|c|c|c|c|c|c|c|}
\hline \multirow[t]{2}{*}{ Level } & \multirow{2}{*}{$\begin{array}{c}\text { Wt. of } \\
\text { sample (mg) }\end{array}$} & \multirow{2}{*}{$\begin{array}{c}\text { Wt. of std } \\
\text { added in (mg) }\end{array}$} & \multicolumn{3}{|c|}{$\begin{array}{l}\text { Amount of Niacin } \\
\text { found in (mg) }\end{array}$} & \multirow{2}{*}{$\begin{array}{l}\text { Mean } \\
(\mathrm{mg})\end{array}$} & \multirow[t]{2}{*}{ S.D } & \multirow[t]{2}{*}{ \%R.S.I } \\
\hline & & & 1 & 2 & 3 & & & \\
\hline 0 & 1352.66 & 0 & 1000.35 & 1000.19 & 1000.17 & 1000.24 & 0.10 & 0.01 \\
\hline 50 & 1349.25 & 501.48 & 1501.48 & 1502.32 & 1504.80 & 1502.87 & 1.73 & 0.11 \\
\hline 100 & 1351.41 & 1001.12 & 2000.35 & 2000.14 & 2000.18 & 2000.22 & 0.11 & 0.01 \\
\hline 150 & 1351.23 & 1501.21 & 2512.36 & 2521.46 & 2521.48 & 2518.43 & 5.26 & 0.21 \\
\hline
\end{tabular}

Percent Recovery $=\frac{N\left(\sum X Y\right)-\left(\sum X\right)\left(\sum Y\right)}{N\left(\sum X^{2}\right)-\left(\sum X\right)^{2}} \times 100$, Where, $N=$ Number of observations; $X=$ Amount of the standard added (mg); $Y=$ Amount of the standard found (mg).

Table 2. Accuracy of Niacin.

\begin{tabular}{ccccc}
\hline Level & $\mathbf{X}$ & $\mathbf{Y}$ & $\mathbf{X}^{\mathbf{2}}$ & $\mathbf{X ~ Y}$ \\
\hline $\mathbf{0}$ & $3 \times 0$ & $3 \times 1000.24$ & $3 \times(0.00)^{2}$ & $3 \times 0 \times 1000.24$ \\
$\mathbf{1}$ & $3 \times 501.48$ & $3 \times 1502.87$ & $3 \times(501.48)^{2}$ & $3 \times 500.10 \times 1502.87$ \\
$\mathbf{2}$ & $3 \times 1001.12$ & $3 \times 2000.22$ & $3 \times(1001.12)^{2}$ & $3 \times 1000.02 \times 2000.22$ \\
$\mathbf{3}$ & $3 \times 1501.21$ & $3 \times 2518.43$ & $3 \times(1501.21)^{2}$ & $3 \times 1500.06 \times 2518.43$ \\
$\Sigma$ & 9011.43 & 21065.28 & 9770627.04 & 19588924.19 \\
\hline
\end{tabular}

$\left(\sum X\right)^{2} \quad 81205870.64$

No. of Observations $\mathrm{N}=12$

Therefore \% Recovery $=\frac{12(19588924.19)-(9011.43) \cdot(21065.28)}{12(37552304.73)-(10519061.37)} \times 100$

$$
\begin{aligned}
& =\frac{45238794.13}{45022865.76} \times 100 \\
& =100.48 \%
\end{aligned}
$$


Table 3. Accuracy of Simvastatin.

\begin{tabular}{|c|c|c|c|c|c|c|c|c|}
\hline \multirow[t]{2}{*}{ Level } & \multirow{2}{*}{$\begin{array}{c}\text { Wt. of } \\
\text { sample (mg) }\end{array}$} & \multirow{2}{*}{$\begin{array}{c}\text { Wt. of std } \\
\text { added in (mg) }\end{array}$} & \multicolumn{3}{|c|}{$\begin{array}{l}\text { Amount of Simvas- } \\
\text { tatin found in (mg) }\end{array}$} & \multirow{2}{*}{$\begin{array}{c}\text { Mean } \\
(\mathrm{mg})\end{array}$} & \multirow{2}{*}{ S.D } & \multirow{2}{*}{ \%R.S.D } \\
\hline & & & 1 & 2 & 3 & & & \\
\hline 0 & 1352.66 & 0 & 20.03 & 20.10 & 20.21 & 20.11 & 0.09 & 0.45 \\
\hline 50 & 1349.25 & 10.21 & 30.25 & 30.16 & 30.29 & 30.23 & 0.07 & 0.22 \\
\hline 100 & 1351.41 & 20.23 & 40.23 & 40.16 & 40.52 & 40.30 & 0.19 & 0.47 \\
\hline 150 & 1351.23 & 30.15 & 50.12 & 50.23 & 50.16 & 50.17 & 0.06 & 0.11 \\
\hline
\end{tabular}

Table 4. Accuracy of Simvastatin.

\begin{tabular}{ccccc}
\hline Level & $\mathbf{X}$ & $\mathbf{Y}$ & $\mathbf{X}^{\mathbf{2}}$ & $\mathbf{X ~ Y}$ \\
\hline $\mathbf{0}$ & $3 \times 0$ & $3 \times 20.11$ & $3 \times(0.00)^{2}$ & $3 \times 0 \times 20.11$ \\
$\mathbf{1}$ & $3 \times 10.21$ & $3 \times 30.23$ & $3 \times(10.21)^{2}$ & $3 \times 10.11 \times 30.23$ \\
$\mathbf{2}$ & $3 \times 20.23$ & $3 \times 40.30$ & $3 \times(20.23)^{2}$ & $3 \times 20.74 \times 40.30$ \\
$\mathbf{3}$ & $3 \times 30.15$ & $3 \times 50.17$ & $3 \times(30.15)^{2}$ & $3 \times 30.16 \times 50.17$ \\
$\Sigma$ & 181.77 & 422.43 & 4367.56 & 7909.63 \\
\hline
\end{tabular}

$\left(\sum x\right)^{2}$

33040.33

No. of Observations $\mathrm{N}=12$

Therefore $\%$ Recovery $=\frac{12(7909.63)-(181.77) \cdot(422.43)}{12(33040.33)-(4267.56)} \times 100$

$$
\begin{aligned}
& =\frac{18134.09}{18170.37} \times 100 \\
& =99.80 \%
\end{aligned}
$$

Table 5. Precision of the proposed HPTLC method.

\begin{tabular}{ccccccc}
\hline \multirow{2}{*}{ Analyte } & \multicolumn{3}{c}{ Mean Peak Area } & \multirow{2}{*}{ Mean } & S.D. & \% R.S.D \\
\cline { 2 - 4 } & DAY 1 & DAY 2 & DAY 3 & & & \\
\hline \multirow{3}{*}{ Niacin } & 16250.39 & 16389.00 & 16309.86 & 16316.42 & 69.54 & 0.43 \\
& 32423.63 & 32438.20 & 32453.41 & 32438.41 & 14.89 & 0.05 \\
& 48207.62 & 48485.72 & 48529.63 & 48407.66 & 174.62 & 0.36 \\
\multirow{3}{*}{ Simvastatin } & 1154.14 & 1150.11 & 1147.11 & 1150.45 & 3.52 & 0.31 \\
& 2319.85 & 2318.79 & 2349.88 & 2329.51 & 17.65 & 0.76 \\
& 3463.75 & 3474.25 & 3452.86 & 3463.62 & 10.69 & 0.31 \\
\hline
\end{tabular}

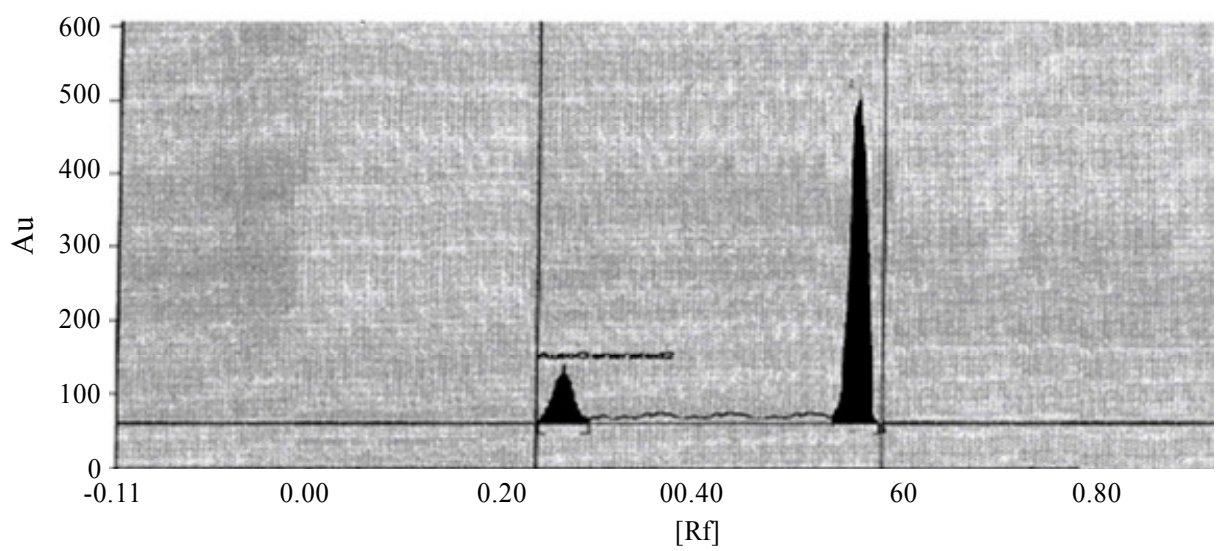

Figure 4. Chromatograms of Niacin and simvastatin in sample solution. 


\section{CONCLUSIONS}

A simple and accurate reverse phase HPTLC method has been developed for the simultaneous determination of niacin and simvastatin. The method was validated by testing its linearity, accuracy, precision and specificity.

\section{ACKNOWLEDGEMENTS}

The authors are great full to precise pharma for providing gift sample of simvastain and niacin.

\section{REFERENCES}

[1] Susman (1995) Niacin reduces triglycerides, increases good cholesterol in diabetics. Doctors Guide Publishing Limited.

[2] Kumar, V. and Shah, R.P., (2008) LC and LC-MS methods for the investigation of polypills for the treatment of cardiovascular diseases: Part 1. Separation of active components and classification of their interaction/degradation products. Saranjit Singh Journal of Pharmaceutical and Biomedical Analysis, 47(3), 508-515.

[3] Chaudhari, B.G., Patel, N.M., Shah, P.B. and Modi, K.P. (2006) Development and validation of a HPTLC method for the simultaneous estimation of atorvastatin calcium and ezetimibe. Indian Journal of pharamaceutical Science, 68(6), 793-796.

[4] Jain, N. and Raghuwanshi, R. (2008) Development and validation of RP-HPTLC method for simultaneous estimation of atorvastatin calcium and fenofibrate in tablet dosage forms. Deepti Jain Indian Journal of pharmaceutical Science, 70(2), 263-265.

[5] Kova', L.N. and Atı'nsky', D.S., (2008) HPLC methods for the determination of simvastatin and atorvastatin. PetrSolich Trac Trends in Analytical Chemistry, 27(4), 352-367.

[6] Jemal, M., Ouyang, Z. and Powell, M.L.(2000) A strategy for a post-method-validation use of incurred biological samples for establishing the acceptability of a liquid chromatography/tandem mass-spectrometric method for quantitation of drugs in biological samples. Journal Pharm Biomed Anal, 16(16), 1538-1547.

[7] Zhang, N., Yang, A., Rogers, J.D. and Zhao, J.J. (2004) Journal Pharm Biomed Anal, 34, 175-187.

[8] Nirogi, R., Mudigonda, K. and Kandikere, V. (2004) Chromatography-mass spectrometry methods for the quantitation of statins in biological samples. Journal of pharmaceutical and Biomedical Analysis. 44, 379-387.

[9] Research \& Development report, may 2000, Australian Government Analytical Laboratories.

[10] Khor, S.-C. and Tee, E.-S. (1996) Development of a
HPLC method for the simultaneous determination of several b-vitamins and ascorbic acid. Malaysian Journal of Nutrition, 2(1), 49-65.

[11] Euro Fir guidelines for assessment of Methods of Analysis KellieWindahi, V Craige Trenerry and Caroline Ward.

[12] Pfuhl, P., Karcher, U., Haring, N., Baumeister, A., Tawab, M.A. and Schubert-Zsilaveez, M. (2005) Simultaneous Determination of Niacin, Niacinamide and Nicotinuric Acid in Human Plasma. Journal of Pharmaceutical and Biomedical Analysis, 36(5), 1045-1052.

[13] Todd, P. A. and Goa, K. L., (1990) Simvastatin: A review of its pharmacological properties and therapeutic potential in hyperlipidaemia. Drugs, 40(4), 583-607.

[14] Pasternak, R.C., Smith, S.C.J., Merz, C.N.B., Grundy, S.M., Cleeman, J. I. and Lenfant, C. (2002) ACC/AHA/ NHLBI clinical advisory on the use and safety of statins. Journal of The American Heart Association, 40, 567-572.

[15] Dave, T. and Diab, E. Analysis of Simvastatin Tablets by High Speed LC. Application Notes 405, Thermo Fisher Scientific, San Jose, 1-6.

[16] Ashfaq, M., Khan, I.U., Quatab, S.S. and Razz, S.N. (2007) Hplc determination of ezetimibe and simvastatin in pharmaceutical formulations. Journal of the Chilean Chemical Society, 52(3), 1220-1224.

[17] Ashfaq, M., Khan, I.U. and Asghar, M.N. (2008) Development and Validation of Liquid Chromatographic Method for Gemfibrozil and Simvastatin in Binary Combination. Journal of the Chilean Chemical Society, 53(3), 1617-1619.

[18] Yang, H., Feng, Y. and Luana, Y. (2003) Determination of Simvastatin in human plasma by liquid chromatography-mass spectrometry. Journal of Chromatography B, 785(2) 369-375.

[19] Basavaiah, K. and Tharpa, K. (2008) The development and validation of visible spectrophotometric methods for simvastatin determination in pure and the tablet dosage forms. Chemical Industry and Chemical Engineering Quarterly, 14(3), 205-210.

[20] Brown, G.B., Zhao, X.-Q., Chait, A., Fisher, L.D., Cheung, M.C., Morese, J.S., Dowdy, A.A., Marino, E. K., Bolson, E. L., Alaupovic, P., Frohlich, J. and Albers, J. J. (2001) Simvastatin and niacin, antioxidant vitamins, or the combination for the prevention of coronary disease. The New England Journal of Medicine, 345(22), 15831592.

[21] Riordan, M. O. and Waknine, Y. (2008) FDA approves combination niacin and simvastatin. Medical News, Medscape.

[22] I.C.H (Q2A) (1994) Note for guidance on validation of analytical methods, definition and terminology. International Conference on Harmonization, Human Medicines Evaluation Unit, the European Agency for the Evaluation of Medicinal Products. 